\title{
Pain catastrophizing in borderline morbidly obese and morbidly obese individuals with osteoarthritic knee pain
}

\author{
Tamara J Somers PhD ${ }^{1}$, Francis J Keefe PhD ${ }^{1}$, James W Carson $\mathrm{PhD}^{2}$, Jennifer J Pells PhD ${ }^{1}$, Lara LaCaille PhD ${ }^{3}$
}

\begin{abstract}
TJ Somers, FJ Keefe, JW Carson, JJ Pells, L LaCaille. Pain catastrophizing in borderline morbidly obese and morbidly obese individuals with osteoarthritic knee pain. Pain Res Manage 2008;13(5):401-406.
\end{abstract}

OBJECTIVE: There is limited information about how morbidly obese osteoarthritis $(\mathrm{OA})$ patients cope with the pain they experience. Pain catastrophizing is an important predictor of pain and adjustment in persons with persistent pain. This may be particularly relevant in the morbidly obese (body mass index [BMI] of $40 \mathrm{~kg} / \mathrm{m}^{2}$ or greater) OA population at risk for increased pain. The present study first examined whether borderline morbidly obese and morbidly obese OA patients report higher levels of pain catastrophizing than a sample of OA patients in the overweight and obese category (BMI between $25 \mathrm{~kg} / \mathrm{m}^{2}$ and $34 \mathrm{~kg} / \mathrm{m}^{2}$ ). Next, it examined how pain catastrophizing is related to important indexes of pain and adjustment in borderline morbidly obese and morbidly obese OA patients.

METHODS: Participants included 43 individuals with knee OA who were borderline morbidly obese or morbidly obese (BMI of $38 \mathrm{~kg} / \mathrm{m}^{2}$ or greater). Participants completed self-report measures of pain catastrophizing, pain, psychological distress, quality of life, binge eating and eating self-efficacy.

RESULTS: The sample of borderline morbidly obese and morbidly obese OA patients reported significantly higher levels of pain catastrophizing $(\mathrm{P}=0.007)$ than a comparison sample of overweight and obese $\mathrm{OA}$ patients. Results suggested that patients who engaged in a high level of pain catastrophizing reported having much more intense and unpleasant pain, higher levels of binge eating, lower self-efficacy for controlling their eating and lower weight-related quality of life $(\mathrm{P}<0.05$ for all $)$.

CONCLUSIONS: Pain catastrophizing is related to pain and adjustment in borderline morbidly obese and morbidly obese OA patients. Clinicians working with this population should consider assessing pain catastrophizing in the patients they treat.

Key Words: Morbidly obese; Osteoarthritis; Pain catastrophizing

\section{La dramatisation de la douleur chez les person- nes à la limite de l'obésité morbide ou présen- tant une morbidité morbide et souffrant de douleurs causées par l'arthrose du genou}

OBJECTIF : On possède peu d'information sur la manière dont les obèses morbides atteints d'arthrose affrontent les douleurs dont ils souffrent. La dramatisation de la douleur est un important prédicteur de la douleur et de l'adaptation chez les personnes souffrant de douleurs persistantes. Ce peut être particulièrement pertinent chez les patients atteints d'arthrose présentant une obésité morbide (indice de masse corporelle [IMC] d'au moins $40 \mathrm{~kg} / \mathrm{m}^{2}$ ) vulnérables à une douleur plus marquée. Dans la présente étude, les auteurs ont d'abord évalué si les patients atteints d'arthrose à la limite de l'obésité morbide ou présentant une obésité morbide déclaraient un plus fort taux de dramatisation de la douleur qu'un échantillon de patients atteints d'arthrose obèses ou faisant de l'embonpoint (IMC de $25 \mathrm{~kg} / \mathrm{m}^{2}$ à $34 \mathrm{~kg} / \mathrm{m}^{2}$ ). Ils ont ensuite examiné dans quelle mesure la dramatisation de la douleur est reliée aux importants indices de la douleur et de l'adaptation chez les patients atteints d'arthrose à la limite de l'obésité morbide ou présentant une obésité morbide.

MÉTHODOLOGIE : Quarante-trois patients atteints d'arthrose du genou à la limite de l'obésité morbide ou présentant une obésité morbide (IMC d'au moins $38 \mathrm{~kg} / \mathrm{m}^{2}$ ) ont participé à l'étude. Ces participants ont déclaré par écrit des mesures de dramatisation de la douleur, de la douleur, de la détresse psychologique, de la qualité de vie, de frénésie alimentaire et d'auto-efficacité de l'alimentation.

RÉSULTATS : L'échantillon de patients atteints d'arthrose à la limite de l'obésité morbide ou présentant une obésité morbide a déclaré des taux considérablement plus élevés de catastrophisation de la douleur $(\mathrm{P}=0,007)$ que l'échantillon comparatif de patients atteints d'arthrose obèses ou faisant de l'embonpoint. Les résultats laissent supposer que les patients qui présentaient une dramatisation de la douleur plus marquée déclaraient avoir des douleurs beaucoup plus intenses et plus déplaisantes, plus de frénésies alimentaires, moins d'auto-efficacité pour contrôler leur alimentation et une moins bonne qualité de vie reliée au poids $(\mathrm{P}<0,05$ pour l'ensemble des facteurs).

CONCLUSIONS : La dramatisation de la douleur est reliée à la douleur et à l'adaptation chez les patients atteints d'arthrose à la limite de l'obésité morbide ou présentant une obésité morbide. Les cliniciens qui travaillent avec cette population devraient envisager d'évaluer la dramatisation de la douleur chez les patients qu'ils traitent.

\footnotetext{
${ }^{1}$ Duke University Medical Center, Durham, North Carolina; ${ }^{2}$ Oregon Health and Science University, Portland, Oregon; ${ }^{3}$ University of Minnesota Duluth, Duluth, Minnesota, USA

Correspondence: Dr Francis J Keefe, Duke University Medical Center, Box 90399, Durham, North Carolina 27708, USA.

Telephone 919-416-3401, fax919-416-3458, e-mail keefe003@mc.duke.edu
} 
$\mathrm{R}^{2}$ ates of knee osteoarthritis (OA) are remarkably higher among morbidly obese individuals than among less obese individuals (17\% versus $10 \%)$ (1). Pain is a primary concern for morbidly obese patients with knee OA. Because of their increased weight, morbidly obese (body mass index [BMI] of $40 \mathrm{~kg} / \mathrm{m}^{2}$ or greater) OA patients experience significant increases in joint stress and load forces on the knees, which causes increased pain (2). The increased pain that occurs during movement often leads to a restricted and physically inactive lifestyle adopted to avoid pain, which paradoxically leads to additional weight gain, and increased pain and disability. Increased knee pain and disability in morbidly obese patients leads to knee replacement surgery at earlier ages than less obese patients (3). Unfortunately, morbidly obese patients also experience more disability postsurgery than less obese patients (4). Morbidly obese individuals typically experience higher levels of psychological distress than less obese individuals (5). Despite these data and the fact that morbid obesity rates are increasing at twice the rate of obesity (52\% versus $24 \%$ from 2000 to 2005) (6), little is known about how morbidly obese OA patients cope with the pain they experience.

Recent advances in cognitive-behavioural pain theory and research suggest that the way an individual thinks about and interprets pain may be important in explaining adjustment to pain in morbidly obese OA patients (7-9). In these patients, pain catastrophizing may be a particularly important variable to consider. Pain catastrophizing refers to the tendency to focus on and magnify pain sensations, and to feel helpless in the face of pain (10). Because morbidly obese OA patients are more likely to experience high levels of pain and disability, they may be more prone to engage in pain catastrophizing than overweight or obese OA patients. To our knowledge, no studies have directly tested whether levels of pain catastrophizing are significantly higher in morbidly obese OA patients than in overweight and obese OA patients. Furthermore, no studies of morbidly obese OA patients have examined how pain catastrophizing relates to important indexes of adjustment to OA pain such as pain, psychological distress, quality of life, binge eating and eating self-efficacy.

In morbidly obese persons experiencing OA pain, pain catastrophizing may not only relate to pain and disability, but also to eating habits. Evidence is emerging that resisting high caloric intake may be particularly challenging for morbidly obese OA patients. Converging lines of research indicate that, in morbidly obese patients, eating may serve to temporarily alleviate physical (eg, pain) and psychological discomfort. Ingesting high-fat meals and high levels of sucrose has been shown to increase pain tolerance (11-19), while estimates suggest that up to one-third of individuals increase their food intake during times of stress $(12,20)$. Morbidly obese OA patients who engage in pain catastrophizing may be at a particular risk for overeating. They may also tend to report low self-efficacy for controlling overeating. To date, no studies of morbidly obese OA patients have examined how pain catastrophizing relates to overeating and selfefficacy for controlling overeating.

The purpose of the present study was twofold. First, it investigated whether borderline morbidly obese and morbidly obese OA patients (BMI of $38 \mathrm{~kg} / \mathrm{m}^{2}$ or greater) report higher levels of pain catastrophizing than a sample of overweight and obese
OA patients (BMI between $25 \mathrm{~kg} / \mathrm{m}^{2}$ and $34 \mathrm{~kg} / \mathrm{m}^{2}$ ). Second, it examined how pain catastrophizing was related to important indexes of adjustment to pain in borderline morbidly obese and morbidly obese OA patients (eg, pain, psychological distress, quality of life, binge eating and self-efficacy for controlling overeating).

\section{Participants and procedures}

\section{METHODS}

Participants in the present study included 43 individuals diagnosed with OA of the knees, with knee pain persisting for six months or longer, and who were borderline morbidly obese or morbidly obese (BMI of $38 \mathrm{~kg} / \mathrm{m}^{2}$ or greater). Participants were recruited through the Orthopedic Surgery Clinic at Duke University Medical Center (Durham, North Carolina, USA). Participants completed a series of study measures and provided demographic and medical information. A comparison group of 157 individuals diagnosed as having OA of the knees, with knee pain persisting for six months or longer, and who were overweight or obese (BMI between $25 \mathrm{~kg} / \mathrm{m}^{2}$ and $34 \mathrm{~kg} / \mathrm{m}^{2}$ ), was used to examine differences in pain catastrophizing. The comparison group was recruited through the Rheumatology, Orthopedic Surgery and Pain Management clinics at Duke University Medical Center, and consisted of volunteers for a treatment outcome study being conducted in the laboratory. Comparison group participants received bilateral knee $\mathrm{x}$-rays, a medical evaluation and completed a series of study measures. Data used in the present paper included only age, sex, race, BMI and pain catastrophizing. All participants gave informed consent, and the study protocols were approved by the institutional review board.

\section{Measures}

Pain catastrophizing: Pain catastrophizing was measured with the catastrophizing subscale of the Coping Strategies Questionnaire (21). Respondents rated the frequency of use of each of the six items on the catastrophizing subscale of the Coping Strategies Questionnaire using a seven-point scale ranging from 0 (never) to 6 (always). Higher scores indicate greater levels of pain catastrophizing. The pain catastrophizing scale has demonstrated good internal consistency in previous work (21), as it did in the present study (Cronbach's alpha $=0.81$ ).

Pain: Pain intensity and unpleasantness were assessed with a $0 \mathrm{~mm}$ to $100 \mathrm{~mm}$ visual analogue scale. Participants were asked to "mark the scale below to indicate the average level of pain intensity you have had in the last day" and to "mark the scale below to indicate the average level of pain unpleasantness you have had in the last day". Visual analogue scales are widely used in pain research (22), and numerous studies have supported their validity, reliability and sensitivity (23).

Psychological distress: Psychological distress was measured with the Symptom Checklist-90-R (24). Each of its 90 items is rated on a 0 (not at all) to 4 (extremely) Likert-type scale to indicate the degree of distress. The Symptom Checklist-90-R has nine symptom dimension scales (somatization, obsessivecompulsive, interpersonal sensitivity, depression, anxiety, hostility, phobic anxiety, paranoid ideation and psychoticism). A summary measure, the Global Severity Index (GSI), was used in the present study. It is computed by summing the scores on 
the nine symptom subscales and additional items that are unique to the GSI, then dividing the sum by the total number of responses. Higher scores indicate greater psychological distress. Validity studies reviewed in the Ninth Mental Measurements Yearbook (25) support the use of the GSI as a global index of psychological distress.

Impact of weight on quality of life: The Impact of Weight on Quality of Life-Lite (26) is a 31-item instrument that assesses the impact of weight on quality of life across five domains (physical functioning, self esteem, sexual life, public distress and work). Examples of items include: "Because of my weight I don't receive appropriate raises, promotions, or recognition of my work"; "Because of my weight I worry about fitting into seats in public places"; "Because of my weight, I don't like myself"; and "Because of my weight I have little or no sexual desire". Participants rated each item on a scale from $1=$ never true to $5=$ always true. Scores are summed to yield a total scale score, with higher scores indicating greater impairment. The Impact of Weight on Quality of Life-Lite has been shown to have good internal consistency (Cronbach's alphas ranging from 0.90 to 0.96) (26), as it did in the present study (Cronbach's alpha $=0.94$ ).

Binge eating: Binge eating tendencies were measured with the 16-item Binge Eating Scale (BES) (27). The BES assesses both behavioural manifestations (eg, eating large amounts of food) and cognitions surrounding a binge episode (eg, guilt, eating cognitions and fear of being unable to stop eating). Each item contains three or four multiple-choice statements. The instructions ask the participant to mark the one that "best describes the way you feel about the problems that you have controlling your eating". For example, one of the behavioural items contains these statements to choose from: "1) I rarely eat so much food that I feel uncomfortable"; "2) Usually about once a month, I eat such a quantity of food, I end up feeling very stuffed"; "3) I have regular periods during the month when I eat large amounts of food, either at mealtime or at snacks"; or "4) I eat so much food that I regularly feel quite uncomfortable after eating and sometimes a bit nauseous". One of the cognition items includes these statements to choose from: "1) I don't think about food a great deal"; "2) I have strong cravings for food but they last only for brief periods of time”; "3) I have days when I can't seem to think about anything else but food"; or "4) Most of my days seem to be pre-occupied with thoughts about food. I feel like I live to eat". Higher scores indicate a greater severity of binge eating. The measure was scored according to the guidelines laid out by Gormally et al (27), and has demonstrated good psychometric properties. The BES demonstrated good reliability in the present sample (Cronbach's alpha $=0.82$ ).

Eating self-efficacy: The Weight Efficacy Life-Style Questionnaire (28) is a 20-item scale used to assess patients' perceived ability to control their weight by resisting eating across five situations (ie, positive emotions, negative emotions, food availability, social context and physical discomfort). Items are rated on a 0 to 9 scale on which $0=$ not confident in inability to resist desire to eat and $9=$ very confident in ability to resist desire to eat. Example items include: "I can resist eating when I am anxious"; "I can resist eating when I am in pain"; "I can resist eating when I am at a party"; and "I can control my eating on weekends". The sum of the ratings for all items provides a global measure with higher scores reflecting greater self-efficacy for resisting eating. The Weight Efficacy Life-Style Questionnaire demonstrated good reliability and validity (29), and demonstrated a high level of internal consistency in the present study (Cronbach's alpha $=0.95$ ).

\section{Statistical analyses}

Descriptive analyses were conducted to summarize patient characteristics and self-report measures. An ANOVA was performed to compare differences between pain catastrophizing in the present sample and the comparison sample of OA patients in the overweight and obese category. Correlational analyses were performed to examine the associations between pain catastrophizing and important indexes of adjustment to OA (eg, pain, psychological distress, weight-related quality of life, binge eating and eating self-efficacy). Linear regression was used to assess the unique contribution of pain catastrophizing when controlling for pain intensity in the outcomes (not including pain) that showed positive correlation. In each regression equation, pain catastrophizing and pain intensity were entered as independent variables.

\section{Participant characteristics}

\section{RESULTS}

The borderline morbidly obese and morbidly obese participants in the present study had a mean ( \pm SD) age of $57.04 \pm 10.04$ years; $72 \%$ were women and $28 \%$ were men. Sixty-five per cent of the sample was white, $33 \%$ was AfricanAmerican and one participant (2\%) reported being more than one race. Participants had an average BMI of $46 \pm 5.47 \mathrm{~kg} / \mathrm{m}^{2}$ (range $38 \mathrm{~kg} / \mathrm{m}^{2}$ to $60 \mathrm{~kg} / \mathrm{m}^{2}$ ), which clearly falls in the morbidly obese range (BMI of $40 \mathrm{~kg} / \mathrm{m}^{2}$ or greater).

Participants in the comparison group had a mean age of $58.87 \pm 10.56$ years; $78 \%$ were women and $22 \%$ were men. Sixty-eight per cent of the comparison sample was white, $29 \%$ was African-American and 3\% reported being another race. Participants in the comparison sample had an average BMI of $31 \pm 2.64 \mathrm{~kg} / \mathrm{m}^{2}$ (range $25 \mathrm{~kg} / \mathrm{m}^{2}$ to $34 \mathrm{~kg} / \mathrm{m}^{2}$ ), which placed them in the overweight and obese category.

There were no significant differences in age, sex or race between the sample and the comparison group. As would be expected, there was a significant difference in BMI between the sample of interest and the comparison sample; $\mathrm{F}(1,197)=615.61, \mathrm{P}<0.001$. Table 1 summarizes demographic and BMI data.

\section{Pain catastrophizing}

The sample of borderline morbidly obese and morbidly obese participants reported an average catastrophizing score of $10.16 \pm 7.15$. This sample of borderline morbidly obese and morbidly obese participants reported significantly higher levels of catastrophizing than the comparison group of overweight and obese $\mathrm{OA}$ patients $(6.86 \pm 6.91, \mathrm{~F}[1,195]=7.56, \mathrm{P}=0.007)$. Table 1 summarizes pain catastrophizing data.

\section{Associations between pain cognitions and indexes of adjustment to $\mathrm{OA}$}

In the sample of morbidly obese OA patients, pain catastrophizing was significantly associated with pain intensity 


\begin{tabular}{|c|c|c|}
\hline & $\begin{array}{l}\text { Study group } \\
(B M I \geq 38, n=43)\end{array}$ & $\begin{array}{l}\text { Comparison group } \\
(B M I=25 \geq 34, n=157)\end{array}$ \\
\hline Age, years & $57.04 \pm 10.04$ & $58.87 \pm 10.56$ \\
\hline $\mathrm{BMI}, \mathrm{kg} / \mathrm{m}^{2 *}$ & $45.96 \pm 5.47$ & $31.19 \pm 2.64$ \\
\hline Women, \% (n) & $72(31)$ & $78(123)$ \\
\hline \multicolumn{3}{|l|}{ Race, \% (n) } \\
\hline African-American & $33(14)$ & $29(46)$ \\
\hline White & $65(28)$ & $68(107)$ \\
\hline Other & $2(1)$ & $3(4)$ \\
\hline Pain catastrophizing* & $10.16 \pm 7.15$ & $6.86 \pm 6.19$ \\
\hline
\end{tabular}

Results presented as mean $\pm S D$ unless otherwise stated. *Significant differences between groups. BMI Body mass index

$(\mathrm{r}=0.47, \mathrm{P}<0.001)$ and pain unpleasantness $(\mathrm{r}=0.40, \mathrm{P}=0.008)$. Patients engaging in high levels of pain catastrophizing reported having pain that was much more intense and unpleasant. Pain catastrophizing was also significantly correlated with binge eating $(r=0.39, P=0.01)$, eating self-efficacy $(r=-0.32$, $\mathrm{P}=0.04)$ and impact of weight on overall quality of life $(\mathrm{r}=0.40$, $\mathrm{P}=0.01$ ). Patients engaging in high levels of pain catastrophizing reported higher levels of binge eating, lower eating self-efficacy and lower overall weight-related quality of life. Pain catastrophizing approached a significant association with psychological distress $(\mathrm{r}=0.26, \mathrm{P}=0.12)$.

Three regression analyses were performed while controlling for pain intensity to explore the unique contribution of pain catastrophizing to the outcomes, as indicated by significant correlations (eg, binge eating, eating self-efficacy and impact of weight on overall quality of life). First, pain catastrophizing and pain intensity explained $17 \%$ of the variance in binge eating $(\mathrm{P}=0.03)$, with only pain catastrophizing as a significant independent predictor $(\beta=0.46, t=2.66, \mathrm{P}=0.01)$. Next, pain catastrophizing and pain intensity accounted for $17 \%$ of the variance $(\mathrm{P}=0.03)$ in the impact of weight on overall quality of life; again, only pain catastrophizing ( $\beta=0.34, t=2.01, P=0.05)$ was a unique predictor in this equation. The final regression equation examining eating selfefficacy was not significant.

\section{DISCUSSION}

The present study is the first to examine pain catastrophizing in a group of borderline morbidly obese and morbidly obese $\mathrm{OA}$ patients. One of the most interesting findings of the present study was that borderline morbidly obese and morbidly obese OA patients (BMI of $38 \mathrm{~kg} / \mathrm{m}^{2}$ or greater) reported significantly higher levels of pain catastrophizing than a comparison sample of $\mathrm{OA}$ patients in the overweight and obese category (BMI between $25 \mathrm{~kg} / \mathrm{m}^{2}$ and $34 \mathrm{~kg} / \mathrm{m}^{2}$ ). The magnitude of the differences in pain catastrophizing was notable, with borderline morbidly obese and morbidly obese OA patients reporting a level of pain catastrophizing more than $40 \%$ higher than the comparison group of overweight and obese OA patients.
There is growing concern about patients who, in the face of arthritis pain, engage in high levels of pain catastrophizing (30). The present study found that borderline morbidly obese and morbidly obese OA patients, who were prone to engage in catastrophizing, experienced pain that was much more intense and unpleasant. Future studies are needed to replicate our findings regarding the link between pain catastrophizing and pain reporting in borderline morbidly obese and morbidly obese OA patients, and to explore how pain catastrophizing in these patients relates to fundamental aspects of pain perception, such as judgments of controlled noxious stimuli and their neural correlates.

To our knowledge, the present study is the first to examine how pain catastrophizing relates to binge eating behaviours and appraisals of eating control in borderline morbidly obese and morbidly obese OA patients. We found that borderline morbidly obese and morbidly obese OA patients who were prone to pain catastrophizing were much more likely to engage in binge eating and to have lower self-efficacy for controlling their overeating. Those who were prone to catastrophizing were also more likely to experience a lower weight-related quality of life. Taken together, these findings suggest that pain catastrophizing may be related in important ways to eating in borderline morbidly obese and morbidly obese OA patients.

One possibility is that morbidly obese OA patients who engage in pain catastrophizing may, in the face of pain, engage in binge eating as a way of soothing their emotional distress or helping them cope with pain. Along these lines, there is emerging evidence that increasing food intake can reduce psychological distress and alleviate acute pain (11-20). Although binge eating may provide acute pain and distress relief in morbidly obese OA patients, increased eating can promote a vicious cycle that results in increased weight, increased pain, increased eating, and so on.

Our findings regarding pain catastrophizing in borderline morbidly obese and morbidly obese OA patients have two important clinical implications. First, they suggest that clinicians working with borderline morbidly obese and morbidly obese OA patients should be more aware of pain catastrophizing in the patients they treat. It could be useful, for example, to include an assessment of pain catastrophizing in the clinical evaluation of borderline morbidly obese and morbidly obese OA patients. The feasibility of assessing pain catastrophizing in clinical practice is enhanced by the recent development of brief (one- to two-item) pain catastrophizing scales that are easy to score, and are both reliable and valid (31). Second, identifying borderline morbidly obese and morbidly obese OA patients who are prone to pain catastrophizing could lead to more timely referral of patients for interventions designed to reduce pain catastrophizing. Pain catastrophizing is a modifiable pain cognition (32), and reductions in pain catastrophizing could potentially improve the patient's pain and quality of life.

In the morbidly obese OA patient, pain catastrophizing could be addressed using two interventions based on cognitivebehavioural theory - pain coping skills training (33-40) and lifestyle behavioural weight management (41-43). Pain coping skills training educates patients about the effects that thoughts, feelings and behaviours can have on pain, and teaches them 
skills for managing pain and decreasing pain catastrophizing. Lifestyle behavioural weight-loss programs educate patients on how weight is impacted by psychosocial (eg, pain catastrophizing) and behavioural factors, and teach patients behavioural strategies for modifying these factors $(44,45)$.

\section{SUMMARY}

The present study is the first to demonstrate significant relationships between pain catastrophizing and indexes of $\mathrm{OA}$ pain and adjustment in a sample of borderline morbidly obese and morbidly obese OA patients. Although morbid obesity is a problem for many persons with $\mathrm{OA}$, these individuals are

\section{REFERENCES}

1. Must A, Spadano J, Coakley EH, Field AE, Colditz G, Dietz WH.

The disease burden associated with overweight and obesity. JAMA 1999;282:1523-9.

2. Felson DT, Zhang Y, Anthony JM, Naimark A, Anderson JJ. Weight loss reduces the risk for symptomatic knee osteoarthritis in women. The Framingham Study. Ann Intern Med 1992;116:535-9.

3. Changulani M, Kalairajah Y, Peel T, Field RE. The relationship between obesity and the age at which hip and knee replacement is undertaken. J Bone Joint Surg Br 2008;90:360-3.

4. Amin AK, Clayton RA, Patton JT, Gaston M, Cook RE, Brenkel IJ. Total knee replacement in morbidly obese patients. Results of a prospective, matched study. J Bone Joint Surg Br 2006;88:1321-6.

5. Wadden TA, Butryn ML, Sarwer DB, et al. Comparison of psychosocial status in treatment-seeking women with class III vs. class I-II obesity. Obesity (Silver Spring) 2006;14(Suppl 2):90S-8S.

6. Sturm R. Increases in morbid obesity in the USA: 2000-2005. Public Health 2007;121:492-6.

7. Keefe FJ, Lefebvre JC, Egert JR, Affleck G, Sullivan MJ, Caldwell DS. The relationship of gender to pain, pain behavior, and disability in osteoarthritis patients: The role of catastrophizing. Pain 2000;87:325-34.

8. Keefe FJ, Caldwell DS, Martinez S, Nunley J, Beckham J, Williams DA. Analyzing pain in rheumatoid arthritis patients. Pain coping strategies in patients who have had knee replacement surgery. Pain 1991;46:153-60.

9. France CR, Keefe FJ, Emery CF, et al. Laboratory pain perception and clinical pain in post-menopausal women and age-matched men with osteoarthritis: Relationship to pain coping and hormonal status. Pain 2004;112:274-81.

10. Sullivan MJ, Thorn B, Haythornthwaite JA, et al. Theoretical perspectives on the relation between catastrophizing and pain. Clin J Pain 2001;17:52-64.

11. Macht M, Haupt C, Ellgring $H$. The perceived function of eating is changed during examination stress: A field study. Eat Behav 2005;6:109-12.

12. Ozier AD, Kendrick OW, Leeper JD, Knol LL, Perko M, Burnham J. Overweight and obesity are associated with emotionand stress-related eating as measured by the Eating and Appraisal Due to Emotions and Stress Questionnaire. J Am Diet Assoc 2008;108:49-56.

13. Miller A, Barr RG, Young SN. The cold pressor test in children: Methodological aspects and the analgesic effect of intraoral sucrose. Pain 1994;56:175-83.

14. Blass EM, Shide DJ. Endogenous cholecystokinin reduces vocalization in isolated 10-day-old rats. Behav Neurosci 1993; 107:488-92.

15. Harrison D, Johnston L, Loughnan P. Oral sucrose for procedural pain in sick hospitalized infants: a randomized-controlled trial. J Paediatr Child Health 2003;39:591-7. (Erratum in 2005;41:535).

16. Johnston CC, Stremler RL, Stevens BJ, Horton LJ. Effectiveness of oral sucrose and simulated rocking on pain response in preterm neonates. Pain 1997;72:193-9.

17. Smith BA, Blass EM. Taste-mediated calming in premature, preterm, and full-term human infants. Dev Psychol 1996;32:1084-9. rarely included in intervention research studies. As the rates of morbid obesity and morbid obesity-related $\mathrm{OA}$ increase $(1,6)$, understanding how to intervene to decrease pain and disability in this population is critical. Our findings regarding the links between pain catastrophizing and adjustment raise the intriguing possibility that intervening to decrease pain catastrophizing could lead to decreases in pain and disability in morbidly obese OA patients.

ACKNOWLEDGEMENTS: The present study was supported by NIH Grants \# 1PO1AR50245 and \#R01AR054626.
18. Mukherjee K, Mathur R, Nayar U. Nociceptive responses to chronic stress of restraint and noxious stimuli in sucrose fed rats. J In Soc Invest Stress 2001;17:297-305.

19. Mukherjee K, Mathur R, Nayar U. Hyperalgesic response in rats fed sucrose from weaning to adulthood: Role of VMH. Pharmacol Biochem Behav 2002;73:601-10.

20. Macht M. How emotions affect eating: A five-way model. Appetite 2008;50:1-11.

21. Rosenstiel AK, Keefe FJ. The use of coping strategies in chronic low back pain patients: Relationship to patient characteristics and current adjustment. Pain 1983;17:33-44.

22. Jensen MP, Karoly P. Self-report scales and procedures for assessing pain in adults. In: Turk DC, Melzack R, eds. Handbook of Pain Assessment. New York: Guilford Press, 1992:131-5.

23. Jensen MP, Karoly P, Braver KS. The measurement of clinical pain intensity: A comparison of six methods. Pain 1986;27:117-26.

24. Derogatis LR. SCL-90-R: Administration, Scoring and Procedures Manual - II. Towson: Maryland Clinical Psychometric Research, 1983.

25. Mitchell JV Jr, ed. The Ninth Mental Measurements Yearbook. Lincoln: The University of Nebraska Press, 1985.

26. Kolotkin RL, Crosby RD, Kosloski KD, Williams GR. Development of a brief measure to assess quality of life in obesity. Obes Res 2001;9:102-11.

27. Gormally J, Black S, Daston S, Rardin D. The assessment of binge eating severity among obese persons. Addict Behav 1982;7:47-55.

28. Clark MM, Abrams DB, Niaura RS, Eaton CA, Rossi JS. Self-efficacy in weight management. J Consult Clin Psychol 1991;59:739-44.

29. Dutton GR, Martin PD, Rhode PC, Brantley PJ. Use of the weight efficacy lifestyle questionnaire with African American women: Validation and extension of previous findings. Eat Behav 2004;5:375-84.

30. Lefebvre JC, Keefe FJ. Memory for pain: The relationship of pain catastrophizing to the recall of daily rheumatoid arthritis pain. Clin J Pain 2002;18:56-63.

31. Jensen MP, Keefe FJ, Lefebvre JC, Romano JM, Turner JA. One- and two-item measures of pain beliefs and coping strategies. Pain 2003;104:453-69.

32. Thorn BE, Pence LB, Ward LC, et al. A randomized clinical trial of targeted cognitive behavioral treatment to reduce catastrophizing in chronic headache sufferers. J Pain 2007;8:938-49.

33. Keefe FJ, Caldwell DS, Williams DA, et al. Pain coping skills training in the management of osteoarthritic knee pain: A comparative study. Behav Ther 1990;21:49-62.

34. Keefe FJ, Caldwell DS, Williams, DA, et al. Pain coping skills training in the management of osteoarthritic knee pain-II: Follow-up results. Behav Ther 1990;21:435-47.

35. Bradley LA, Young LD, Anderson KO, et al. Effects of psychological therapy on pain behavior of rheumatoid arthritis patients. Treatment outcome and six-month follow-up. Arthritis Rheum 1987;30:1105-14.

36. Bradley L, Young L, Anderson K, et al. Effects of cognitivebehavior therapy on rheumatoid arthritis pain behavior: One year follow-up. In: Dubner R, Gebhart GF, Bond MR. Proceedings of the 5 th World Congress on Pain. Amsterdam: Elsevier, 1988:310-4. 
37. Appelbaum KA, Blanchard EB, Hickling EJ, Alfonso M. Cognitive behavioral treatment of a veteran population with moderate to severe rheumatoid arthritis. Behav Ther 1988;19:489-502.

38. Parker JC, Frank RG, Beck NC, et al. Pain management in rheumatoid arthritis patients. A cognitive-behavioral approach. Arthritis Rheum 1988;31:593-601.

39. Radojevic V, Nicassio PM, Weisman MH. Behavioral intervention with and without family support for rheumatoid arthritis. Behav Ther 1992;23:13-30.

40. Keefe FJ, Caldwell DS, Baucom D, et al. Spouse-assisted coping skills training in the management of knee pain in osteoarthritis: Long-term followup results. Arthritis Care Res 1999;12:101-11.

41. Messier SP, Loeser RF, Mitchell MN, et al. Exercise and weight loss in obese older adults with knee osteoarthritis: A preliminary study. J Am Geriatr Soc 2000;48:1062-72.
42. Messier SP, Loeser RF, Miller GD, et al. Exercise and dietary weight loss in overweight and obese older adults with knee osteoarthritis: The Arthritis, Diet, and Activity Promotion Trial. Arthritis Rheum 2004;50:1501-10.

43. Miller GD, Nicklas BJ, Davis C, Loeser RF, Lenchik L, Messier SP. Intensive weight loss program improves physical function in older obese adults with knee osteoarthritis. Obesity (Silver Spring) 2006;14:1219-30

44. de Jong JR, Vlaeyen JW, Onghena P, Goossens ME, Geilen M, Mulder H. Fear of movement/(re)injury in chronic low back pain: Education or exposure in vivo as mediator to fear reduction? Clin J Pain 2005;21:9-17.

45. Vlaeyen JW, de Jong J, Geilen M, Heuts PH, van Breukelen G. The treatment of fear of movement/(re)injury in chronic low back pain: Further evidence on the effectiveness of exposure in vivo. Clin J Pain 2002;18:251-61. 


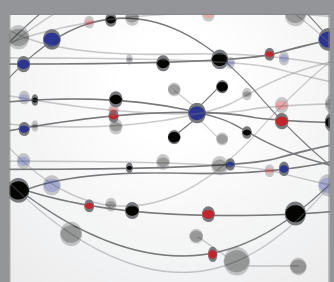

The Scientific World Journal
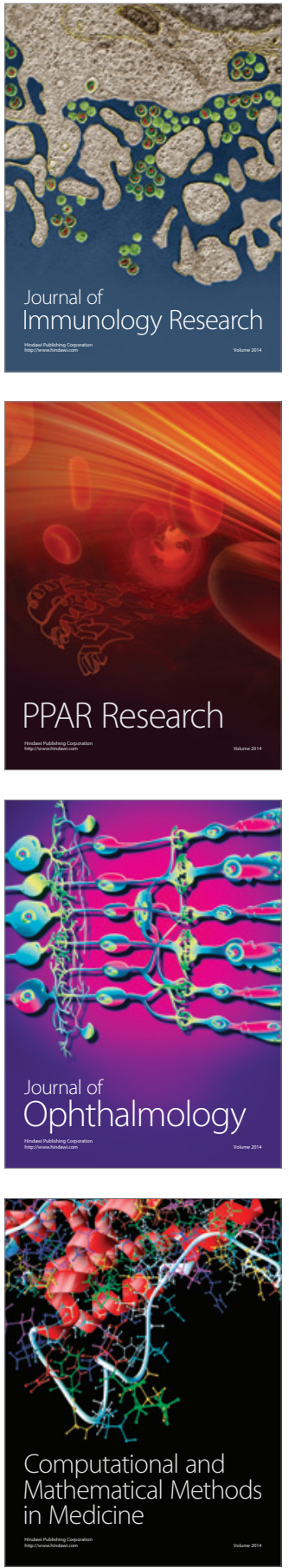

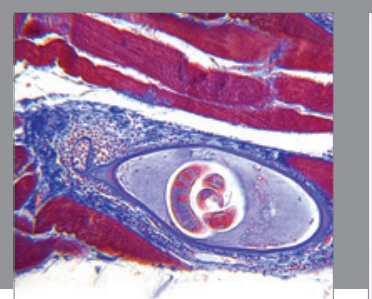

Gastroenterology Research and Practice

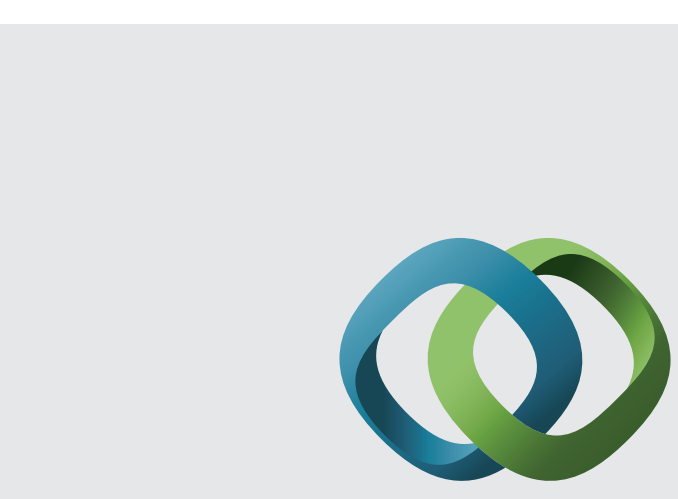

\section{Hindawi}

Submit your manuscripts at

http://www.hindawi.com
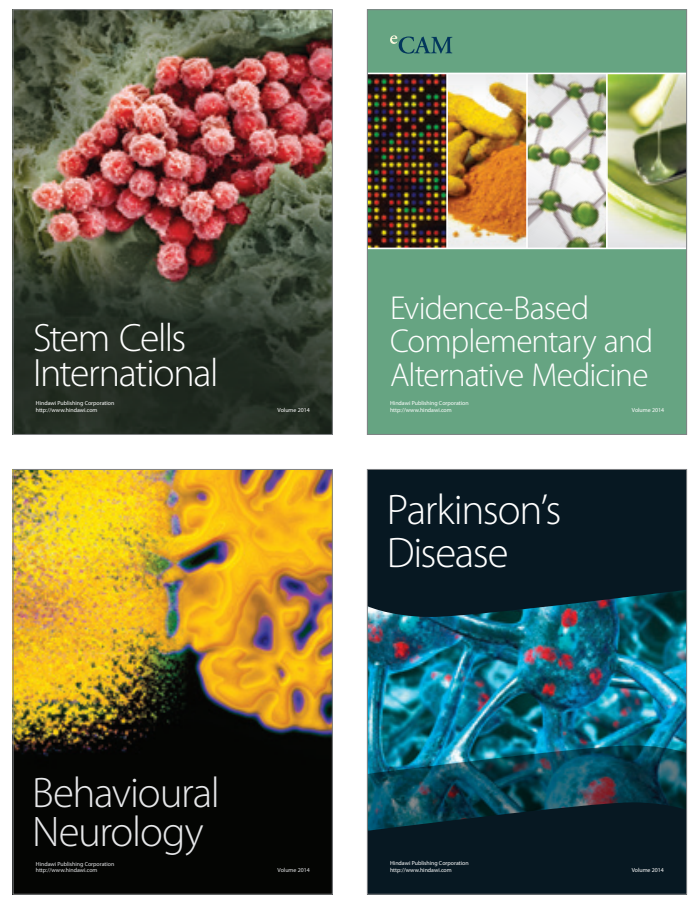
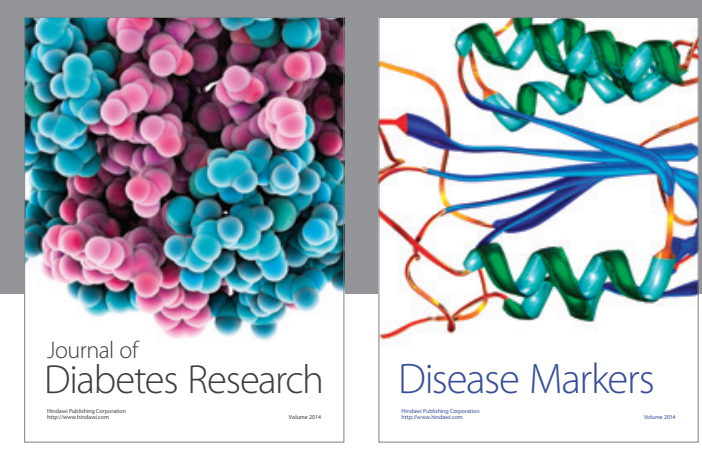

Disease Markers
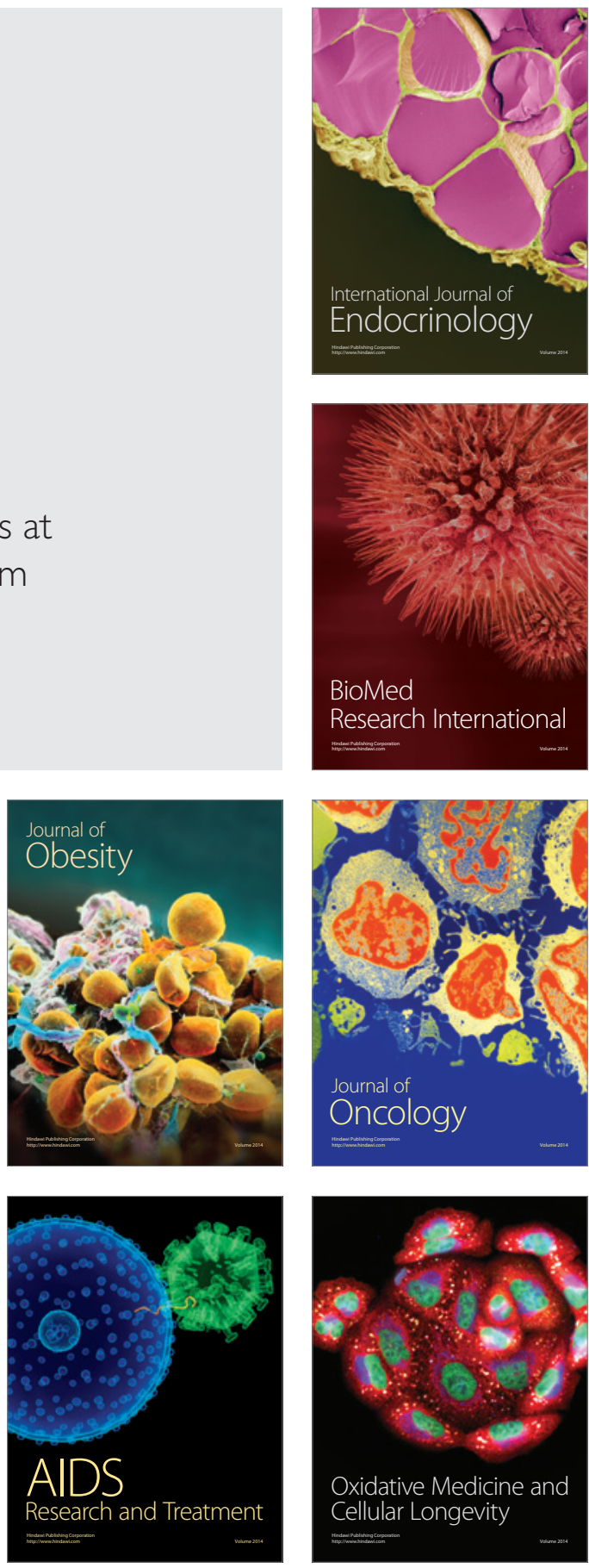